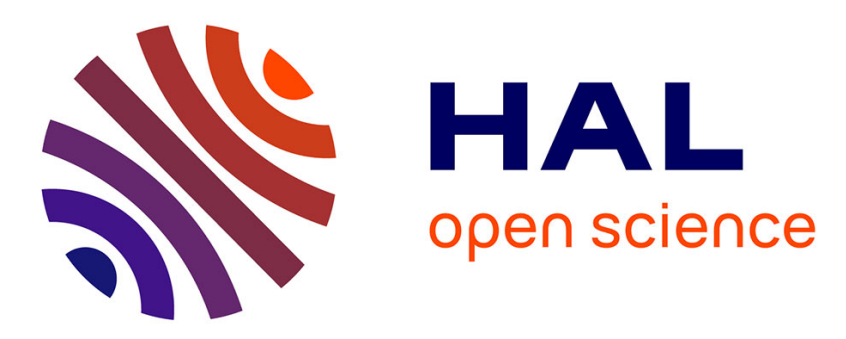

\title{
Evaluation of the local heat losses in solids through an optical method
}

\author{
N. Tankovsky, D. Ivanov, B. Yordanov
}

\section{To cite this version:}

N. Tankovsky, D. Ivanov, B. Yordanov. Evaluation of the local heat losses in solids through an optical method. Revue de Physique Appliquée, 1986, 21 (5), pp.339-341. 10.1051/rphysap:01986002105033900 . jpa-00245451

\section{HAL Id: jpa-00245451 https://hal.science/jpa-00245451}

Submitted on 1 Jan 1986

HAL is a multi-disciplinary open access archive for the deposit and dissemination of scientific research documents, whether they are published or not. The documents may come from teaching and research institutions in France or abroad, or from public or private research centers.
L'archive ouverte pluridisciplinaire HAL, est destinée au dépôt et à la diffusion de documents scientifiques de niveau recherche, publiés ou non, émanant des établissements d'enseignement et de recherche français ou étrangers, des laboratoires publics ou privés. 
Classification

Physics Abstracts

$07.60 \mathrm{~L}-44.30$

\title{
Evaluation of the local heat losses in solids through an optical method
}

\author{
N. Tankovsky, D. Ivanov and B. Yordanov \\ Department of Solid State Physics, Faculty of Physics, \\ Sofia University, 5 A. Ivanov Blvd, Sofia-1126, Bulgaria \\ (Reçu le 15 août 1985, révisé les 26 novembre 1985 et 27 janvier 1986, accepté le 31 janvier 1986)
}

\begin{abstract}
Résumé. - L'influence des pertes thermiques sur la déformation élastique du profil d'une surface provoquée par l'échauffement d'un faisceau laser continu a été évaluée dans cet article. Une comparaison des résultats expérimentaux obtenus à l'aide d'une méthode opto-interférrométrique aux résultats calculés analytiquement nous a permis de définir sans ambiguité le coefficient de transfert de chaleur du solide avec le milieu extérieur.
\end{abstract}

Abstract. - The influence of the heat losses on the topography of the surface thermoelastic deformations, caused by a CW laser is used in the present work. Comparison of the experimental results, obtained by an optical-interferrometric method, with analytical calculations allows to define unambiguously the heat transfer coefficient in solids.

The problem of convective heat-transfer through a boundary solid-gas is complex enough to be treated directly, either theoretically or experimentally [1]. On the other hand, its practical importance is great in modern technology and machine building. In this connection all contributions to this problem are actual and useful. In the present paper a contactless, non-destructive method for the evaluation of the thermal loss in solids is presented, based on opticalinterferrometric measuring of the surface thermoelastic deformations (STD). The surface heating source is a focused CW laser spot and this allows one to estimate the heat transfer coefficient in a local region of the examined surface.

Experiments have shown $[2,3]$, that when a $\mathrm{CW}$ laser is focused on the surface of a solid, in a short period of time the temperature field and the corresponding mechanical strains achieve a steady state. Evidently, the static regime is due to the equilibrium between the input energy flux, on the one hand, and the energy flux losses comprising the thermal flow into the solid and out to the surrounding media plus the mechanical energy needed to sustain the deformations of the solid, on the other hand.
Having a sufficiently accurate and non-destructive method for measuring the static STD, which is described elsewhere $[2,3]$ one can put forward the following question. Is there any thermal parameter of the medium (or a group of parameters) which unambiguously defines the character of the STD profile ? If so, it would be easy to define this parameter experimentally. A theoretical analysis is to be made in order to answer best to this question.

A theoretical description of the static STD can be obtained after the steady-state equation of the heat conduction and the equation of the static thermoelasticity are solved together with the corresponding boundary conditions at the surface of the half-space. This problem is solved exactly only for isotropic media. The steady-state temperature distribution and the static stresses which occur by the action of a surface circular heat source with radius $r_{0}$ (the radius of the focused heating laser spot) have been calculated [4]. Since the geometry of the problem is axisymmetrical the temperature field and the induced stresses are expressed in cylindrical coordinates as follows :

$$
\begin{gathered}
T=q r_{0} \int_{0}^{\infty} J_{1}\left(p r_{0}\right) J_{0}(p r) \frac{\mathrm{e}^{-p z}}{p k+h} \mathrm{~d} p \\
\sigma_{r r}=-Q \int_{0}^{\infty} J_{1}\left(p r_{0}\right) J_{1}(p r) \frac{\mathrm{e}^{-p z}}{p r(p k+h)} \mathrm{d} p \\
\sigma_{\varphi \varphi}=-Q \int_{0}^{\infty} J_{1}\left(p r_{0}\right) J_{0}(p r) \frac{\mathrm{e}^{-p z}}{p k+h} \mathrm{~d} p-\sigma_{r r}
\end{gathered}
$$


with boundary conditions :

$$
\left.\sigma_{z z}\right|_{z=0}=\left.\sigma_{r z}\right|_{z=0}=0 ;\left.\quad k \frac{\partial T}{\partial z}\right|_{z=0}=\left.h T\right|_{z=0}+\left\{\begin{array}{lll}
q & \text { for } & 0<r \leqslant r_{0} \\
0 & \text { for } & r>r_{0}
\end{array} .\right.
$$

Here $Q=\alpha q r_{0} \mu\left(\frac{3 \lambda+2 \mu}{\lambda+\mu}\right), \alpha$ is the coefficient of linear thermal expansion, $\lambda$ and $\mu$ are elastic constants of Lame, $k$ is the solid thermal conductivity, $q$ is the thermal power density, $J_{1}$ and $J_{0}$ are Bessel functions of first and zero order respectively and $h$ is the heat transfert coefficient. It is defined by the Newton formula $h=q /\left(T-T_{0}\right)$ and depends on the thermal, physical and dynamic characteristics of solid and gas. The heat transfer comprises several mechanisms-convection, radiation and conduction.

In order to define the component of the displacement vector along the $Z$-axis, normal to the surface, we make use of the relations between stresses and displacement vector components, expressed in cylindrical coordinates :

$$
\begin{aligned}
& \lambda\left(\frac{\partial U_{r}}{\partial r}+\frac{U_{r}}{r}\right)+(\lambda+2 \mu) \frac{\partial U_{z}}{\partial z}-(3 \lambda+2 \mu) \alpha\left(T-T_{0}\right)=0 \\
& \lambda\left(\frac{\partial U_{r}}{\partial r}+\frac{\partial U_{z}}{\partial z}\right)+(\lambda+2 \mu) \frac{U_{r}}{r}-(3 \lambda+2 \mu) \alpha\left(T-T_{0}\right)=\sigma_{\varphi \varphi} \\
& \lambda\left(\frac{\partial U_{z}}{\partial z}+\frac{U_{r}}{r}\right)+(\lambda+2 \mu) \frac{\partial U_{r}}{\partial r}-(3 \lambda+2 \mu) \alpha\left(T-T_{0}\right)=\sigma_{r r} .
\end{aligned}
$$

After some trivial transformations we can obtain from (3) the following relation :

$$
U_{z}=-\frac{\lambda}{2 \mu(3 \lambda+2 \mu)} \int\left(\sigma_{r r}+\sigma_{\varphi \varphi}\right) \mathrm{d} z+\int \alpha\left(T-T_{0}\right) \mathrm{d} z
$$

Finally, after substitution (1) and (4) and integrating we obtain the formula for the normal component of surface displacement :

$$
U_{z}(r, z=0)=\frac{\alpha q r_{0}(3 \lambda+2 \mu)}{2(\lambda+\mu)} \int_{0}^{\infty} \frac{J_{1}\left(p r_{0}\right) J_{0}(p r)}{p(p k+h)} \mathrm{d} p
$$

The integral (5) is numerically calculated and the result is shown graphically in figure 1 . The curves in figure 1 are normalized by dividing the STD amplitude to the maximum value at $r=r_{0}$ and the character of the profile is studied. We must note that the curves $U_{z}(r)$ may be normalized at $r=0$, which is more natural, but since the experimental results were defined for $r \geqslant r_{0}$ we chose a normalization at $r=r_{0}$. By varying the parameters $k$ and $h$ a family of curves is obtained, which can unambiguously be identified by the ratio $h / k$, so that this ratio is really the parameter that can be defined from the STD profile. The curves 1 and 3 (Fig. 1) correspond to the extreme values $h / k \rightarrow \infty$ and $h / k \rightarrow 0$. All the curves lying in the area between 1 and 3 correspond to values within the interval $0<h / k<\infty$. Curve 2 corresponds to $h / k=1\left[\mathrm{~m}^{-1}\right]$

As a present application we can define the heat loss in quartz and glass samples, using the experimental results obtained in reference [2]. The normalized experimental STD profiles are presented in figure 2. The obtained approximate value of the heat loss in quartz is about 10 times greater than in glass $-h \simeq 1 \mathrm{~W} / \mathrm{m}^{2} \mathrm{~K}$ for quartz and $h \simeq 10^{-1} \mathrm{~W} / \mathrm{m}^{2} \mathrm{~K}$

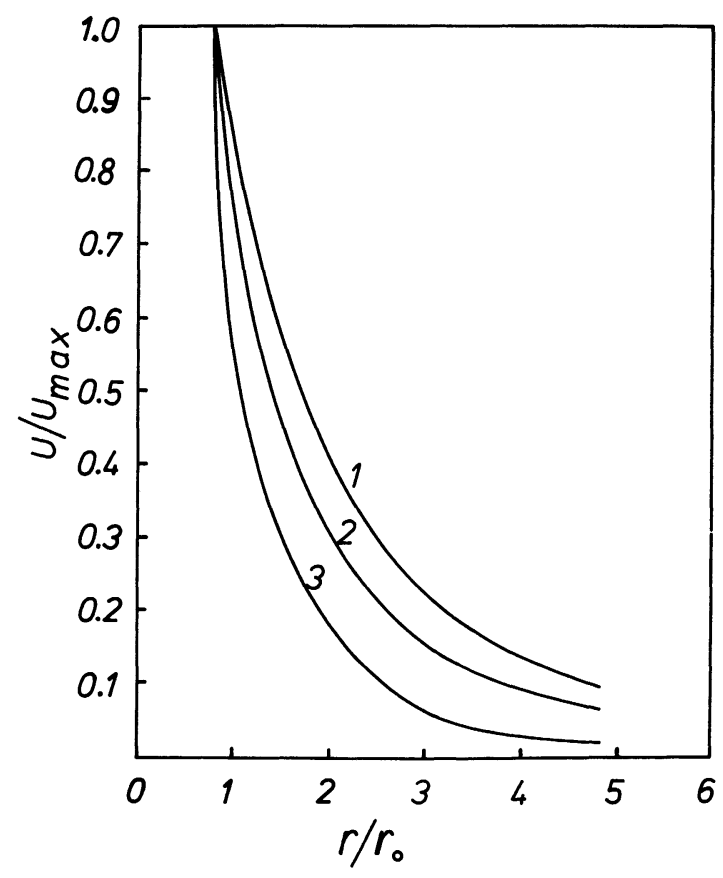

Fig. 1. - Theoretically calculated STD profiles $: h / k \rightarrow \infty$ for curve $1, h / k=1\left[\mathrm{~m}^{-1}\right]$ for curve $2, h / k \rightarrow 0$ for curve 3 . 


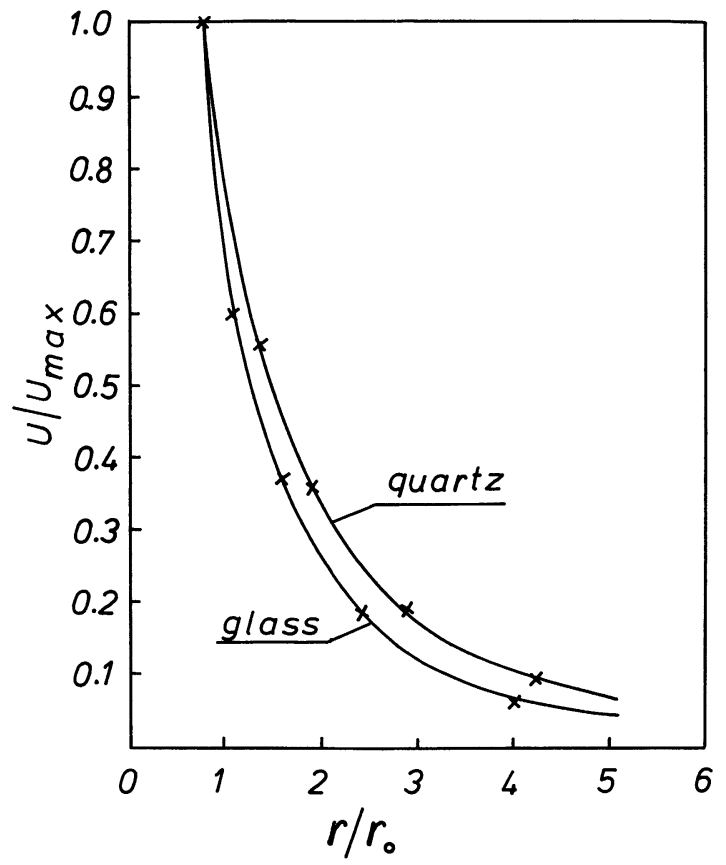

Fig. 2. - Experimentally obtained STD profiles for quartz and glass sample.

for glass. The data given in reference [2] are not very accurate because 1) $r_{0}$ are not carefully measured; 2) the samples are cubes, not big enough, so that the lateral walls influence the STD profiles as shown in reference [3]; 3) a mismatch error occurs when defining the pairs signal-coordinate by comparison of two photos.

The accuracy of the method for the evaluation of the heat losses by comparing the experimental and theoretical curves is rather low because the curves $\frac{U_{z}}{U_{\max }}\left(\frac{h}{k}\right)$ are very close to one another. But the accuracy may be improved if numerical values are compared and statistically processed. This can be achieved if the signal detection is electronic and data are computer analysed.

Evidently, the procedure for experimental evaluation of $h / k$ may be the following. A laser beam, focused at the surface will induce STD, whose topography is measured with the help of interference fringes of a probing laser. The relative phase change of the fringes at every point of the surface may be detected by a position photodetector or by an ordinary photodetector and an automatically driven scanning table. Thus the signal is locked with the coordinate and the pair signal-coordinate is fed to a computer for analysis. The parameter $h / k$ is varied until the difference between the numerical results of theory and experiment is minimized. The results from many coordinatepoints along the curve can be statistically processed. The error caused by the assumption that the laser spot is equivalent to a homogeneous circular heat source is manifested for values of $r$ near to $r_{0}$. That is why we can minimize this error simply by choosing coordinates not too close to $r_{0}$, i.e. $r>r_{0}$.

In conclusion we can say that a method is presented which allows one to evaluate the local heat losses in solids by measuring the topography of static surface thermoelastic deformations created by a focused CW laser. The method can be generalized for bulk thermal sources since the theory of their surface thermoelastic response is well developed [4].

\section{References}

[1] JAKOB, Heat Transfer (John Wiley) 1949.

[2] Tankovsky, N., Ivanov, D., Burov, J., Revue Phys. Appl. 19 (1984) 631.

[3] Tankovsky, N., Ivanov, D., Appl. Phys. Lett. 46 (7) (1985) 639.

[4] Koliano, J., Nulin, A., Temperature Stresses by Bulk Sources in Russian (Nauk. Dumka, Kiev) 1983. 